\title{
Embriogénesis no zigótica en Passiflora maliformis
}

\author{
Nonzygotic Embryogenesis in Passiflora maliformis
}

\section{Sandra Carolina Bernal Moreno, Lyda Catherine Duarte Rodríguez, María de los Angeles Bohórquez Quintero*, Eyda Johanna Araque, y José Constantino Pacheco}

Universidad Pedagógica y Tecnológica de Colombia, Facultad de Ciencias, Escuela de Biología, Laboratorio de Cultivo de Tejidos Vegetales BIOPLASMAUPTC, Avenida Central del Norte 39-115, Tunja, Colombia. lab.bioplasma@uptc.edu.co

${ }^{*}$ Autor de correspondencia

E-mail Sandra Bernal: carolina.bernal.m@gmail.com

E-mail Lyda Duarte: lycadr4@hotmail.com

E-mail María Bohórquez: mariadelosangeles.bohorquez@uptc.edu.co

E-mail Eyda Araque: eyda.araque@uptc.edu.co

E-mail José Pacheco: jocpach@gmail.com

\section{Resumen}

La importancia económica, ecológica y medicinal de las pasifloras ha fomentado el desarrollo de investigaciones multidisciplinarias en estas plantas. En cultivo in vitro, la embriogénesis no zigótica representa una alternativa para regeneración de plantas; no obstante, esta técnica ha presentado dificultades en la reproducibilidad de los protocolos, así como formación de ciertos embriones y plántulas anormales en algunas especies. En este estudio se evaluó la capacidad morfogénica de embriones zigóticos maduros (EZM) de Passiflora maliformis L para desarrollar embriones no zigóticos (ENZ), y posterior regeneración de plántulas. Se ensayó una etapa de inducción en la que se probaron 12 tratamientos en medio MS+VitB5 suplementado con 2,4-D, KIN y BA adicionados solos o combinados y, otra, de expresión en MS, MS con Carbón activado (CA) o MS con reguladores de crecimiento (RC) en concentraciones reducidas a $1 / 10$ parte de las adicionadas en la etapa inducción. Altos porcentajes, $70 \%$, de regenerantes fueron obtenidos en el medio suplementado con $1 \mathrm{mgL}^{-1} \mathrm{BA}$ y transferidos a medio de expresión $\mathrm{MS}$, así como en el medio con $1 \mathrm{mgL}^{-1} \mathrm{BA}+3 \mathrm{mgL}^{-1} 2,4-\mathrm{D}$, y transferidos a medio de expresión con CA, $60 \%$. El 70\% de las plántulas regeneradas se desarrollaron exitosamente en invernadero. Este trabajo es el primero que aborda la expresión del potencial embriogénico de EZM de $P$. maliformis induciendo exitosamente respuestas embriogénicas no zigóticas a través de rutas directas e indirectas; los resultados obtenidos son aplicables al conocimiento de la embriogénesis no zigótica en otras pasifloras, con fines de mejoramiento y uso comercial.

Palabras Clave: Embriogénesis somática; In vitro; morfogénesis; regenerantes somáticos; pasifloras.

\section{Abstract}

The economic, ecological and medical significance of passion fruits has encouraged the development of multidisciplinary research in this group. In vitro culture, non-zygotic embryogenesis represents an alternative for plant regeneration; however, this technique has presented difficulties in the reproducibility of protocols as well as the development of certain embryos and abnormal plantlets in some species. We assessed in Passiflora maliformis $L$ the morphogenic capacity in the mature zygotic embryos (MZE) to develop nonzygotic embryos (NZE), and subsequent plantlets regeneration. We tested an induction stage with 12 treatments in MS + VitB5 medium supplemented with 2,4-D, KIN and BA added alone or combined and, another with a MS, MS with Activated Charcoal (AC) or MS with growth regulators $(G R)$ in $1 / 10$ concentrations reduced to $1 / 10$ of those added in the induction stage. We obtained high percentages, $70 \%$, of regenerants in the medium supplemented with $1 \mathrm{mgL}^{-1} \mathrm{BA}$ and transferred to the $\mathrm{MS}$ expression medium, as well as in the medium with $1 \mathrm{mgL}^{-1} \mathrm{BA}+3 \mathrm{mgL}^{-1}$ 2,4-D, and transferred to the expression medium with $\mathrm{AC}, 60 \%$. $70 \%$ of the regenerated seedlings were successfully grown in the greenhouse. This is the first research that addresses the expression of the MZE embryogenic potential in P. maliformis, inducing a successfully embryogenic non-zygotic responses through direct and indirect routes; the obtained results are relevant to the knowledge of non-zygotic embryogenesis in other passion fruits, for breeding and commercial uses.

Keywords: Somatic embryogenesis; In vitro; morphogenesis; somatic regenerants; passion fruit.

Citación:

Bernal Moreno S.C., L.C. Duarte Rodríguez, M.A. Bohórquez Quintero, E.J. Araque \& J.C. Pacheco. 2018. Embriogénesis no zigótica en Passiflora maliformis. Revista peruana de biología 25(3): 281 - 290 (Agosto 2018). doi: http://dx.doi.org/10.15381//rpb.v25i3.15211

$\begin{array}{ll}\text { Presentado: } & 18 / 01 / 2018 \\ \text { Aceptado: } & 26 / 06 / 2018\end{array}$

Publicado online: 25/09/2018

\section{Información sobre los autores:}

SB, LD realizaron la concepción, diseño, fase experimental, análisis cualitativo y cuantitativo, y textos preliminares del manuscrito. MB, EA realizaron análisis de resultados y discusión, redacción y preparación del manuscrito. JP dirigió la investigación, participó en el diseño, ejecución, análisis, diseño y redacción del manuscrito. Todos los autores revisaron y aprobaron el manuscrito.

Los autores no incurren en conflictos de intereses. 


\section{Introducción}

La familia Passifloraceae comprende aproximadamente 16 géneros distribuidos en regiones tropicales y subtropicales (Pacheco et al. 2016) y fue descrita por Lineo (Linnaeu 1753) (Tavares et al. 2015). El género Passiflora comprende aproximadamente 575 especies (Aguirre-Morales et al. 2016, Jørgensen et al. 2012) distribuidas desde el sur de Argentina hasta el sur de Estados Unidos; además, aproximadamente 20 especies se limitan a las regiones tropicales y subtropicales del Sudeste de Asia, Australia y Nueva Zelanda (Hansen et al. 2006). Colombia es el país con mayor diversidad con cerca de 170 especies reportadas y de ellas 57 son endémicas (Ocampo 2013, Ocampo et al. 2010).

Las especies de Passiflora son de interés por la diversidad y exotismo de sus hojas, flores, frutos y derivados (Abreu et al. 2009), como plantas ornamentales, medicinales, farmacéuticas y para aprovechamiento en la industria cosmética y frutícola (Pacheco et al. 2016). Las más cultivadas son maracuyá (Passiflora edulis $\mathrm{f}$. flavicarpa Degener), granadilla (Passiflora ligularis Juss.) y gulupa (Passiflora edulis f. edulis Sims). Aunque es evidente el gran potencial económico que tienen las especies silvestres y cultivadas, su productividad se ve limitada por falta de variedades ampliamente adaptadas y tolerantes a plagas y patógenos; faltan programas de mejoramiento genético (Pacheco et al. 2016, Zerbini et al. 2008).

La conservación de pasifloras silvestres generalmente se realiza en bancos de semillas, aunque la renovación periódica está limitada por la reducción del potencial de germinación, lo que resulta en la pérdida de materiales. Además, varias especies producen semillas con características específicas que dificultan el almacenamiento en los bancos (Pacheco et al. 2016, VeigaBarbosa et al. 2013). Para superar esta limitación, el uso de metodologías in vitro puede contribuir tanto al aprovechamiento como a la conservación de la diversidad genética del género (Pacheco et al. 2016).

Durante los últimos 50 años se han realizado estudios in vitro en algunas pasifloras, principalmente en maracuyá. Se describió inicialmente la inducción de organogénesis en Passiflora caerulea L. (Nakayama 1966) y en P. edulis f. flavicarpa y Passiflora molissima (Kunth) L. H. Bailey (Moran Robles 1978); desde entonces, diferentes procesos y sistemas de cultivo in vitro se han desarrollaron con éxito, a través de organogénesis y embriogénesis no zigótica (Pacheco et al. 2016), los cuales ofrecen, entre otras, la posibilidad de propagar plantas a gran escala (Pérez-Pérez et al. 2017, Kanwar \& Kumar 2008).

Mientras que la organogénesis in vitro en pasifloras se ha abordado en diferentes investigaciones (Ozarowski \& Thiem 2013) la capacidad embriogénica de estas especies ha sido menos estudiada; Anthony et al. (1999) indujeron embriogénesis en suspensiones celulares de Passiflora gibertii N.E. Br, a partir de explantes foliares y Reis et al. (2007) reportaron embriogénesis indirecta a partir de líneas transformadas de raíz de Passiflora cincinnata Mast. Recientemente, se ha descrito embriogénesis no zigótica indirecta a partir de embriones zigóticos maduros (EZM) de $P$. cincinnata y $P$. edulis (Pinto et al. 2011, Da-Silva et al. 2009). También se han evaluado eventos histológicos y ultraestructurales asociados al proceso embriogénico, para dilucidar los factores relacionados con la adquisición de competencia embriogénica y determinación celular (Pacheco et al. 2016, Rocha et al. 2012).
A pesar de los avances anteriormente reportados, muy pocos estudios de embriogénesis somática se han realizado en especies silvestres (Pacheco et al. 2016, Ozarowski \& Thiem 2013, Guzzo et al. 2004); puesto que para Passiflora maliformis L. no se conocen reportes al respecto, en este trabajo se evaluó la capacidad de expresión morfogénica de EZM de P. maliformis para desarrollar ENZ.

\section{Materiales y métodos}

Material vegetal.- Semillas maduras de $P$. maliformis se obtuvieron de frutos comercializados en el mercado local de Chiscas (Boyacá-Colombia) $\left(06^{\circ} 33^{\prime} \mathrm{N}, 7^{\circ} 29^{\prime} \mathrm{W}\right)$. Las semillas se depositaron en recipientes de vidrio, con agua destilada estéril, para su fermentación durante cuatro días; luego se lavaron con agua corriente para remover el arilo y se colocaron sobre papel absorbente, a temperatura ambiente de $13-15^{\circ} \mathrm{C}$ durante tres días.

Posteriormente, las semillas (Fig. 1A) se escarificaron manualmente escindiendo el borde de la testa y se sumergieron en agua destilada estéril durante tres horas para rehidratar los tejidos. En cámara de flujo laminar, las semillas escarificadas (Fig. 1A) se esterilizaron superficialmente mediante inmersión (1 minuto) en etanol al $70 \%(\mathrm{v} / \mathrm{v})$, seguida por inmersión (20 minutos) en $\mathrm{NaOCl}(5.25 \% \mathrm{p} / \mathrm{v})$ al $2.5 \%$ (v/v) con $0.1 \mathrm{~mL}$ de TWEEN $20 \mathrm{y}$, finalmente, se enjuagaron cinco veces consecutivas en agua destilada estéril (protocolo reportado por Melo-Vieira et al. (2014)). Los (EZM) (Fig. 1A) se aislaron con ayuda de estereoscopio, pinzas y bisturí y se cultivaron individualmente, en posición horizontal, en recipientes de vidrio $(10 \mathrm{~mL})$ con alícuotas de $4 \mathrm{~mL}$ de medio.

Embriogénesis. Durante la etapa de inducción se utilizó un medio base compuesto por sales minerales MS (Murashige \& Skoog 1962), vitaminas B5 (Gamborg et al. 1968), y 30000 $\mathrm{mgL}^{-1}$ de sacarosa, mientras que para la etapa de expresión se utilizó MS. El pH de ambos medios se ajustó a $5.8 \pm 0.1$, se solidificaron con $2800 \mathrm{mgL}^{-1}$ de Phytagel $^{\oplus}$ (Sigma Chemical Co.) y se esterilizaron en autoclave a 15 Psi y $121{ }^{\circ} \mathrm{C}$ por 20 minutos. Los embriones cultivados se incubaron a $24 \pm 2{ }^{\circ} \mathrm{C}$, con una intensidad lumínica de $70-80 \mu \mathrm{mol} \mathrm{m}^{-2} \mathrm{~s}^{-1}$, suministrada por lámparas fluorescentes y, durante la etapa de inducción (30 días) se mantuvieron en oscuridad y durante la fase de expresión y desarrollo (90 días), con fotoperiodo de 16/8 horas.

Al final de la etapa de inducción se evaluó el efecto de los fitorreguladores 2,4-diclorofenoxiacético (2,4-D), 6-bencilaminopurina (BA) y Kinetina (KIN) adicionados al medio base en las concentraciones y combinaciones indicadas en la Tabla 1. Esta etapa se repitió tres veces, y se cultivaron 30 EZM en cada tratamiento.

Los explantes inducidos se transfirieron a diferentes medios de expresión: MS sin reguladores de crecimiento (RC) suplementado con $3000 \mathrm{mgL}^{-1}$ de carbón activado (CA) (EI); MS con los mismos reguladores de crecimiento del medio de inducción pero disminuidos a 1/10 de su concentración (EII) y MS sin reguladores (EIII).

Durante esta etapa, los explantes se subcultivaron cada 30 días en recipientes de vidrio de $100 \mathrm{~mL}$ con alícuotas de 20 $\mathrm{mL}$ de medio.

Desarrollo de plántulas y aclimatización.- Al finalizar la etapa de expresión, los ENZ cotiledonares formados se transfirieron a medio MS suplementado con $3000 \mathrm{mgL}^{-1} \mathrm{de} C A$. Adicionalmente, se ensayó la regeneración de plántulas cultivando 
Tabla 1. Tratamientos ensayados para inducción de embriogénesis no zigótica en embriones zigóticos maduros de Passiflora maliformis.

\begin{tabular}{cccc}
\hline \multirow{2}{*}{ Tratamiento } & \multicolumn{3}{c}{ Reguladores de Crecimiento $\left(\mathrm{mgL}^{-1}\right)$} \\
\cline { 2 - 4 } 1 & $\mathbf{2 , 4 - D}$ & BA & KIN \\
\hline 2 & 1 & 1 & - \\
3 & 3 & 1 & - \\
4 & 5 & 1 & - \\
5 & 1 & - & 1 \\
6 & 3 & - & 1 \\
7 & 5 & - & 1 \\
8 & 1 & - & - \\
9 & 3 & - & - \\
10 & 5 & - & - \\
11 & - & 1 & - \\
12 & - & - & 1 \\
\hline
\end{tabular}

los ENZ sin aislarlos del explante, en MS suplementado con 1 y $2 \mathrm{mgL}^{-1}$ de KIN o BA e incubados a $24 \pm 2{ }^{\circ} \mathrm{C}$ con fotoperiodo de $16 / 8$ horas. Las plántulas regeneradas se transfirieron a macetas plásticas con un sustrato compuesto por tierra y arena $(3: 1)$, se mantuvieron en cuarto de incubación durante dos semanas y, posteriormente en condiciones de invernadero $\left(15-20^{\circ} \mathrm{C}\right)$. Las macetas se cubrieron con polipropileno extensible para mantener la humedad relativa y después de tres semanas se eliminó de forma gradual.

Análisis estadístico.- Para determinar la interacción entre los tratamientos de inducción y de expresión, se aplicó un diseño factorial con tres réplicas, cada réplica consistió de 30 EZM (explantes primarios) para un total de 90 explantes por tratamiento. Se realizó un análisis de varianza univariado (ANOVA) para determinar el efecto de los tratamientos sobre la respuesta embriogénica somática y, se aplicó la prueba de comparación
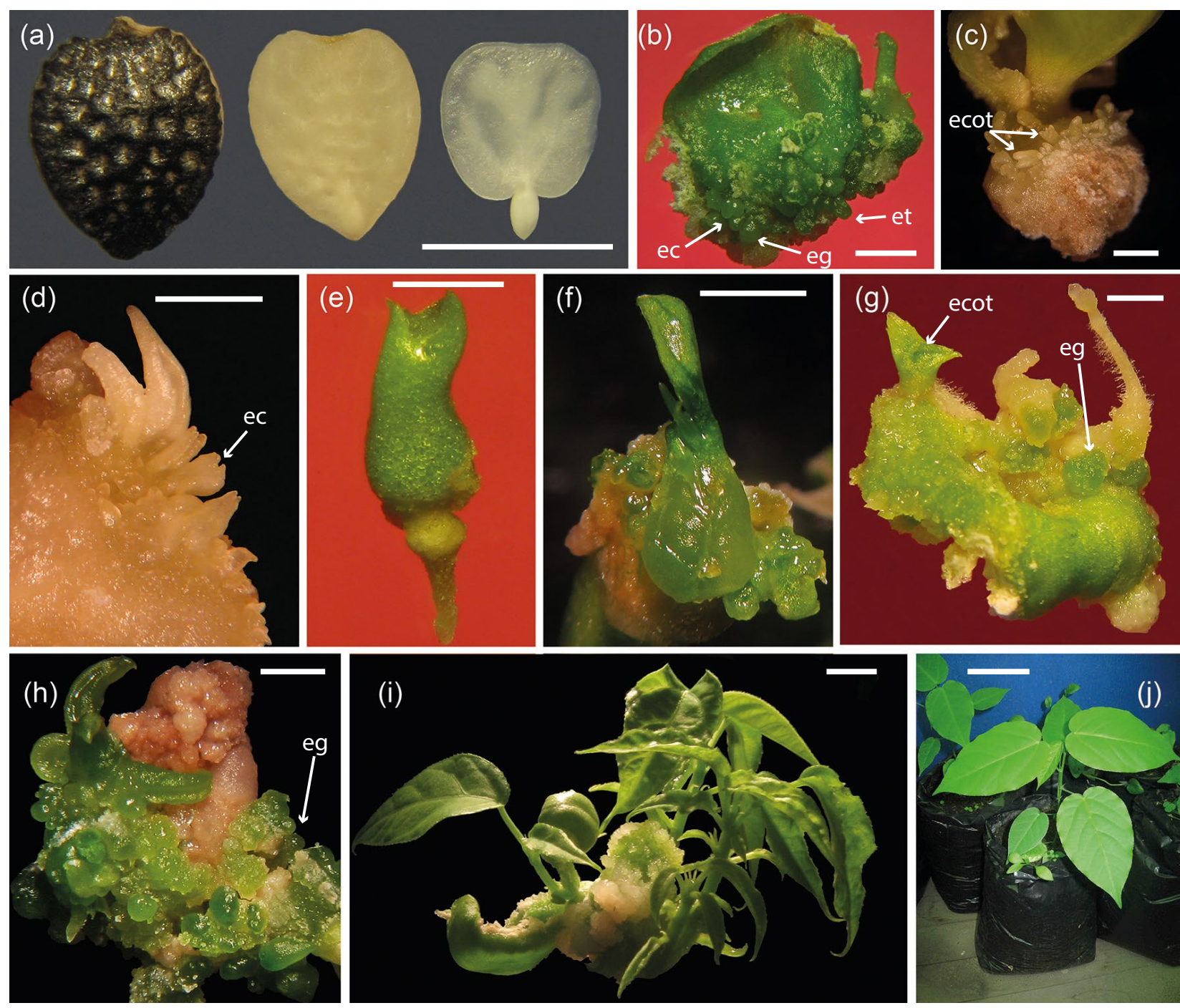

Figura 1. Respuestas embriogénicas no zigóticas de EZM de Passiflora maliformis. (A) Explantes primarios: semilla intacta, semilla sin testa, embrión. (B) Explante embriogénico con embriones en estado corazón (ec), embriones en estado globular (eg) y embriones en estado torpedo (et). (C) Explante con embriones cotiledonares (ecot). (D) Embriones en estado corazón. (E) Embrión en estado torpedo. (F) Embrión en estado cotiledonar. (G) Callo embriogénico con ENZ formados vía indirecta: Embrión en estado globular (eg), embrión en estado cotiledonar (ecot). (H) Embriones no zigóticos formados vía directa e indirecta en diferentes estados de desarrollo. Embrión en estado de corazón, vía directa (ec) y embrión en estado globular, vía indirecta (eg). (I) Brotes en desarrollo a partir de embriones cotiledonares. (J) Plantas regeneradas aclimatizadas en invernadero. Barra $=0.5 \mathrm{~cm}(\mathrm{~A}-\mathrm{I})$; Barra $=10 \mathrm{~cm}(\mathrm{~J})$. 
múltiple LSD (Diferencia mínima significativa) para determinar similitudes y diferencias entre los tratamientos ensayados. Para los análisis se usó el software SAS (SAS Institute 2016).

La cuantificación de regenerantes a partir de ENZ y de plántulas viables después de la aclimatización se calculó en términos porcentuales.

\section{Resultados}

Material vegetal, reguladores de crecimiento y condiciones de cultivo.- Los EZM utilizados como explantes primarios, formados por tejidos muy juveniles, expresaron una gran capacidad morfogénica para el desarrollo de procesos de embriogénesis no zigótica vía directa y/o indirecta (Fig. 1B), observándose la formación de estructuras embrionarias globulares, en forma de corazón, torpedo y cotiledonares (Fig. 1B-F). Las respuestas embriogénicas no zigóticas observadas ponen en evidencia el efecto positivo de los reguladores de crecimiento utilizados, BA, KIN y 2,4-D, en $P$. maliformis; en los tratamientos control no se observó embriogénesis somática. La formación de ENZ y de callo embriogénico se observó con mayor frecuencia en los bordes de los cotiledones, la inserción cotiledonar y en la radícula.

Una temperatura de incubación de los subcultivos de $24 \pm 2$ ${ }^{\circ} \mathrm{C}$, en oscuridad continua durante la etapa de inducción y un fotoperiodo de 16 horas durante la fase de expresión, así como el uso de $2800 \mathrm{mgL}^{-1}$ de Phytagel, fueron condiciones favorables para la expresión de la capacidad embriogénica de los explantes cultivados.

Embriogénesis no zigótica.- En explantes cultivados en medio de inducción con $1 \mathrm{mgL}^{-1} \mathrm{BA}$ (T10) y transferidos a medio de expresión sin RC (EIII), se cuantificó el mayor porcentaje de ENZ (70\%). Respuestas embriogénicas no zigóticas favorables también se observaron en los explantes cultivados en presencia de $1 \mathrm{mgL}^{-1} \mathrm{BA}+3 \mathrm{mgL}^{-1}$ 2,4-D (T2) y que fueron transferidos a medio con CA (EI). En contraste, en los tratamientos de inducción con 1 y $3 \mathrm{mgL}^{-1}$ de 2,4-D (T7 y T8, respectivamente), la expresión de la capacidad embriogénica no superó el 17\% en los medios de expresión EI y EII, mientras que en presencia de $5 \mathrm{mgL}^{-1}$ de 2,4-D (T9 y EI) se cuantificó un 30\% de explantes embriogénicos (Fig. 2).

I) Embriogénesis directa.- El análisis factorial indicó que la efectividad de la estimulación de procesos embriogénicos no zigóticos no se debió al efecto de la interacción entre los tratamientos de inducción (T1-T12) y los medios de expresión (EI-EIII) ( $\mathrm{p}=0.5677 ; \mathrm{p} \geq 0.05)$; no se observó diferencia estadísticamente significativa entre EI, EII y EIII ( $\mathrm{p}=0.1662$; $\mathrm{p} \geq 0.05)$ pero si se observó diferencia entre los tratamientos de inducción $(\mathrm{p}=0 ; \mathrm{p}<0.05)$ determinándose cuatro grupos estadísticos (Fig. 3). El $20 \%$ de explantes embriogénicos registrado en presencia de $1 \mathrm{mgL}^{-1} \mathrm{BA}+1,3$ ó $5 \mathrm{mgL}^{-1}$ de 2,4-D inducción (T1, T2 y T3, respectivamente) y transferidos a medio de expresión con CA (EI) fue mayor al registrado en presencia de $1 \mathrm{mgL}^{-1}$ KIN y/o 2,4-D y transferidos a los tres medios de expresión (EI, EII, EIII).

II) Embriogénesis indirecta.- El análisis factorial indicó que la respuesta embriogénica no zigótica indirecta cuantificada se debió a la interacción entre los tratamientos de inducción y los medios de expresión ( $\mathrm{p}=0$ ), siendo algunos tratamientos significativamente más efectivos (LSD: siete grupos estadísticos) (Fig. 4).

En los explantes cultivados en el tratamiento con $1 \mathrm{mgL}^{-1}$ $\mathrm{BA}+3 \mathrm{mgL}^{-1} 2$,4-D (T2) y transferidos a medio de expresión con CA (EI), se registró el mayor porcentaje (50\%) de explantes

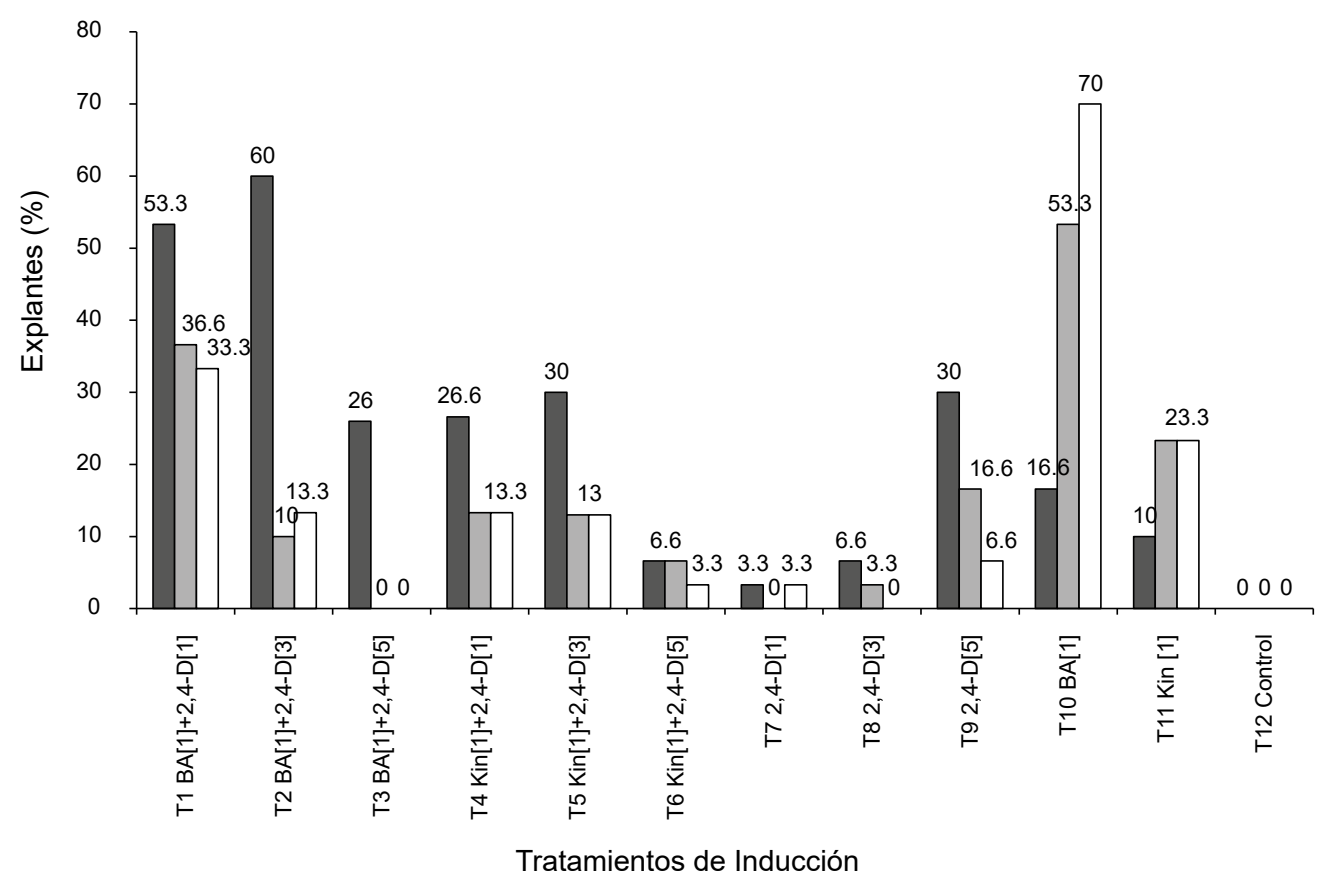

Medios de Expresión:

$\square$ Carbón Activado (E1) $\square$ RC 1/10 (EII) $\square$ Sin RC (EII)

Figura 2. Respuesta embriogénica no zigótica de EZM de Passiflora maliformis. Los números entre paréntesis cuadrados indican la concentración, en $\mathrm{mgL}^{-1}$, de los reguladores de crecimiento utilizados. 


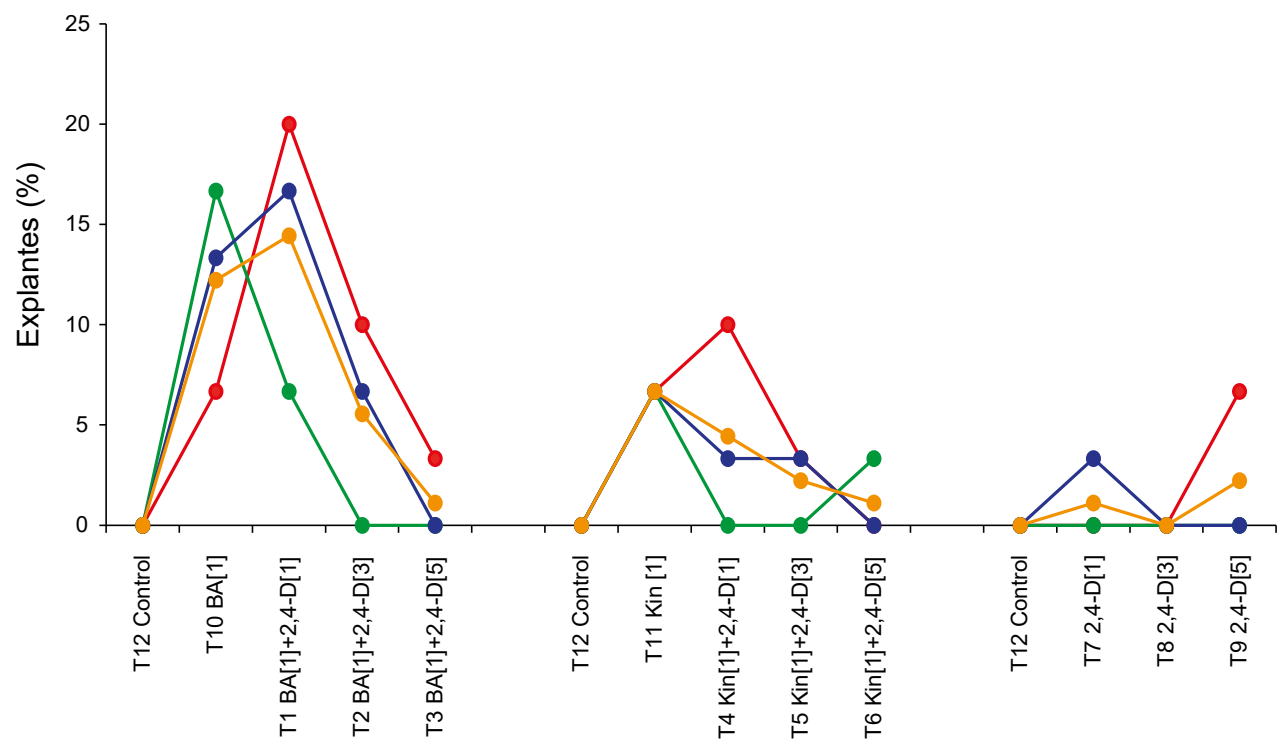

Tratamientos de Inducción

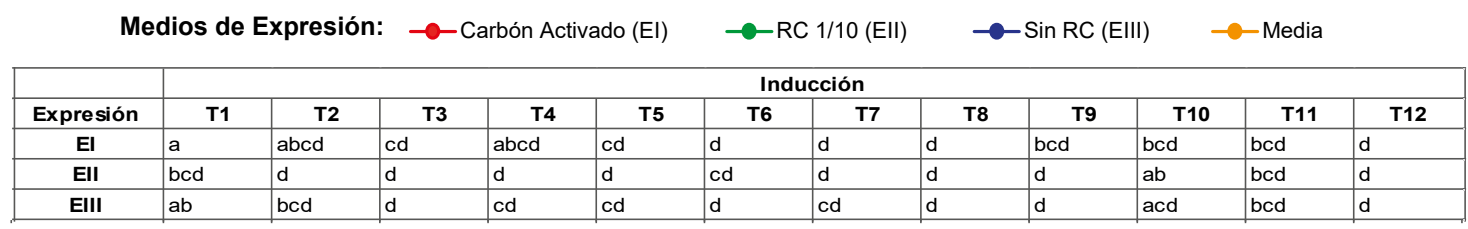

Figura 3. Respuesta embriogénica no zigótica directa de EZM de Passiflora maliformis a partir de EZM. Los números entre paréntesis cuadrados indican la concentración, en $\mathrm{mgL}^{-1}$, de los reguladores de crecimiento utilizados. Letras distintas entre tratamientos indican diferencia significativa, según la prueba de comparación múltiple de diferencia mínima significativa (LSD) $(p \leq 0.05)$.

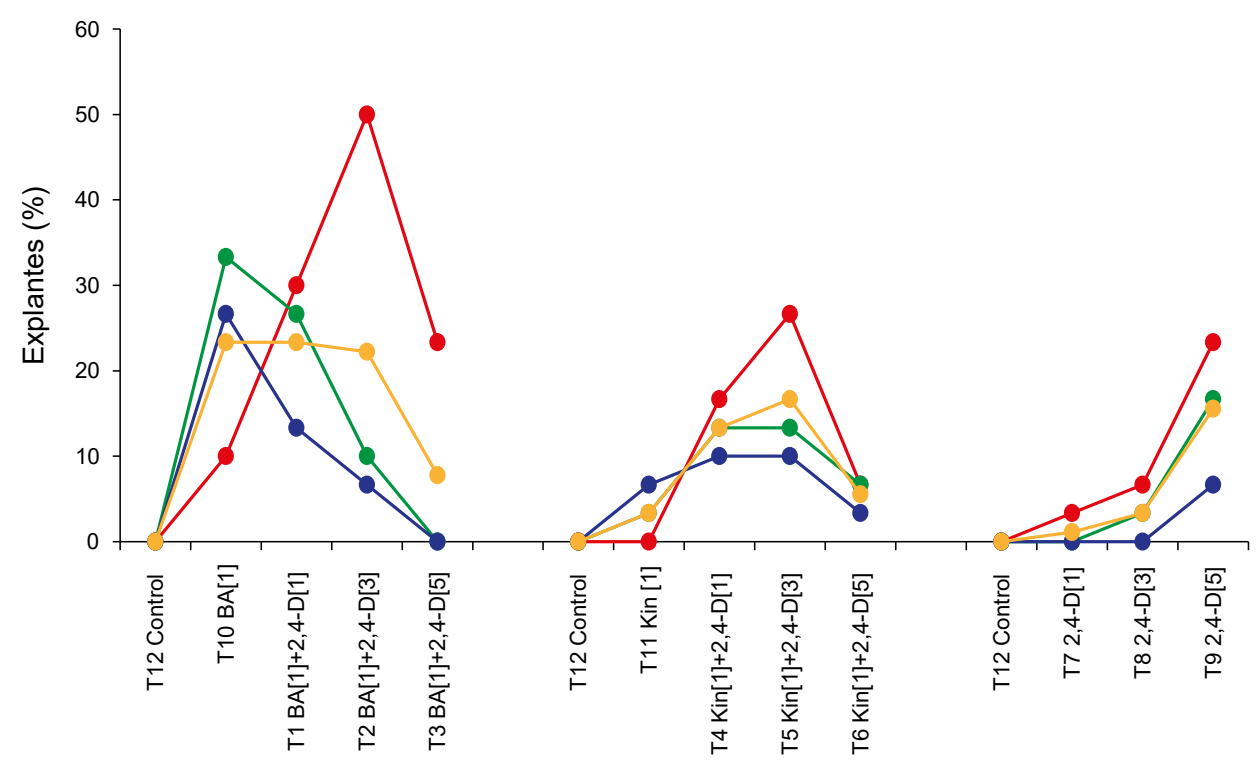

Tratamientos de Inducción

\begin{tabular}{|c|c|c|c|c|c|c|c|c|c|c|c|c|}
\hline \multicolumn{4}{|c|}{ Medios de Expresión: } & \multicolumn{3}{|c|}{ - Carbón Activado (EI) } & \multicolumn{2}{|c|}{- RC 1/10 (EII) } & \multicolumn{2}{|c|}{$-\operatorname{Sin} \mathrm{RC}(\mathrm{EIII})$} & \multicolumn{2}{|c|}{- -Media } \\
\hline & \multicolumn{12}{|c|}{ Inducción } \\
\hline Expresión & T1 & T2 & T3 & T4 & T5 & T6 & T7 & T8 & T9 & T10 & T11 & T12 \\
\hline EI & bc & $a$ & bcde & cdef & bcd & $\mathrm{fg}$ & $\mathrm{fg}$ & $\mathrm{fg}$ & bcde & efg & $g$ & $g$ \\
\hline EII & bcd & efg & $\mathrm{g}$ & defg & defg & $\mathrm{fg}$ & g & $\mathrm{fg}$ & cdef & b & $\mathrm{fg}$ & $g$ \\
\hline EIII & defg & $\mathrm{fg}$ & $g$ & efg & efg & $\mathrm{fg}$ & $\mathrm{g}$ & g & fg & bcd & $\mathrm{fg}$ & $g$ \\
\hline
\end{tabular}

Figura 4. Respuesta embriogénica indirecta de EZM de Passiflora maliformis. Los números entre paréntesis cuadrados indican la concentración de los reguladores de crecimiento utilizada en $\mathrm{mgL}^{-1}$. Letras distintas entre tratamientos indican diferencia significativa, según la prueba de comparación múltiple de diferencia mínima significativa (LSD) ( $p \leq 0.05)$. 


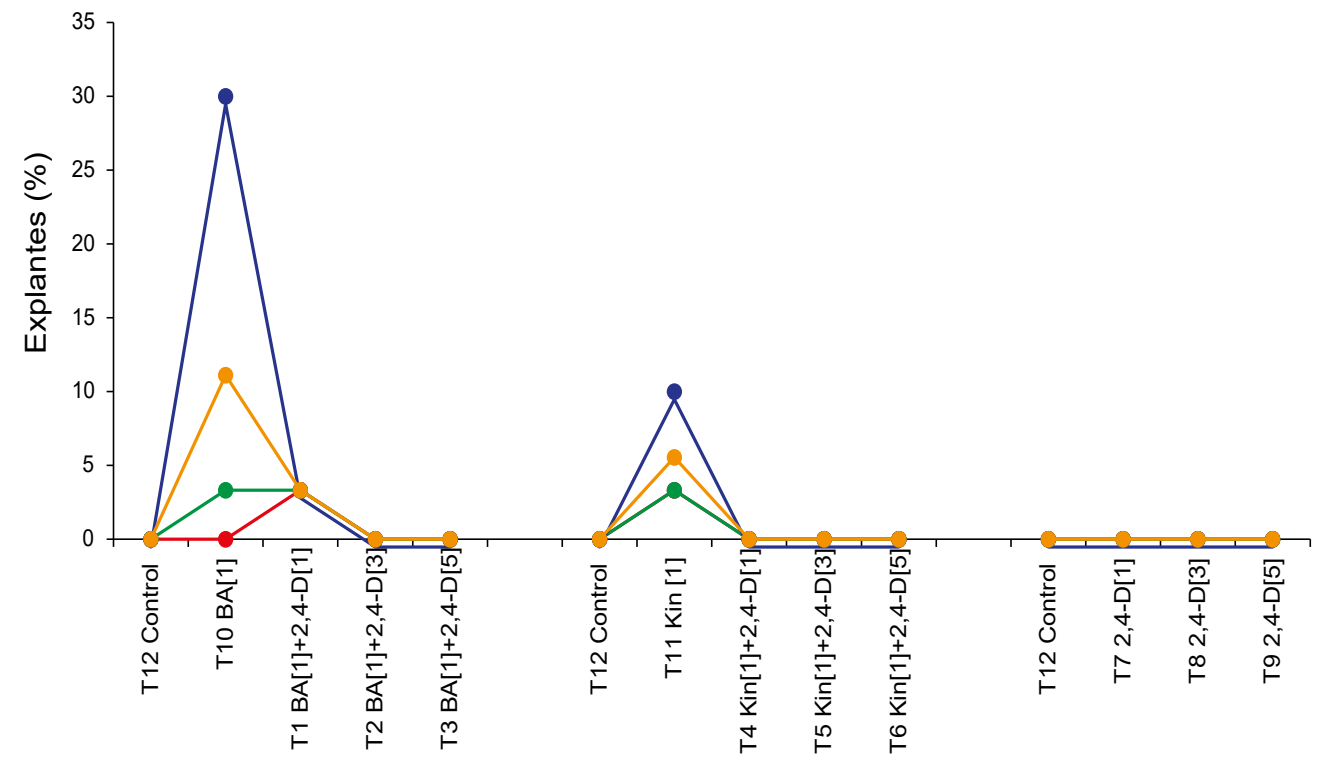

Tratamientos de Inducción

\begin{tabular}{|c|c|c|c|c|c|c|c|c|c|c|c|c|}
\hline \multirow[b]{3}{*}{ Expresión } & \multicolumn{6}{|c|}{-C Carbón Activado (EI) } & \multicolumn{2}{|c|}{$\rightarrow$ RC 1/10 (EII) } & \multicolumn{3}{|c|}{$\bumpeq \operatorname{Sin} \mathrm{RC}(\mathrm{EIII})$} & \multirow[t]{2}{*}{- -Media } \\
\hline & \multicolumn{11}{|c|}{ Inducción } & \\
\hline & $\mathrm{T} 1$ & T2 & $\mathrm{T} 3$ & $\mathrm{~T} 4$ & T5 & T6 & $\mathrm{T} 7$ & T8 & T9 & T10 & T11 & T12 \\
\hline El & c & c & c & c & c & c & c & c & c & c & c & c \\
\hline Ell & c & c & c & c & c & c & c & c & c & c & c & c \\
\hline EIII & c & $\mathrm{c}$ & c & $\mathrm{c}$ & c & c & c & c & c & $\mathrm{a}$ & $b$ & c \\
\hline
\end{tabular}

Figura 5. Respuesta embriogénica no zigótica directa e indirecta desarrollada simultáneamente en los EZM de Passiflora malliformis. Los números en paréntesis cuadrados indican la concentración, en $\mathrm{mgL}^{-1}$, de los reguladores de crecimiento utilizados. Letras distintas entre tratamientos indican diferencia significativa, según la prueba de comparación múltiple de diferencia mínima significativa (LSD) $(p \leq 0.05)$.

que mostraron embriogénesis indirecta, en comparación con los tratamientos en los que se utilizó únicamente $1 \mathrm{mgL}^{-1} \mathrm{de}$ BA (10\%), KIN (0\%) o solo 2,4-D (<23\%). No obstante, se observó que el porcentaje de explantes embriogénicos alcanzó $23 \%$ cuando se incrementó la concentración de 2,4-D hasta 5 $\mathrm{mgL}^{-1}$ (Fig. 4).

La formación de callo en los diferentes medios de inducción, se observó aproximadamente 8 días después de establecidos los cultivos. Los callos obtenidos de color amarillento, verdoso y amarillo verdoso, además de presentar apariencia compacta, mostraron mayor capacidad embriogénica.

III) Embriogénesis directa e indirecta.- El desarrollo simultáneo de procesos embriogénicos directos e indirectos (Fig. $1 \mathrm{H})$ solo se observó en presencia de $1 \mathrm{mgL}^{-1} \mathrm{BA}, 30 \%$ (T10) y $1 \mathrm{mgL}^{-1} \mathrm{KIN}, 10 \%$ (T11), cuando fueron transferidos al medio de expresión EIII (Fig. 5). La simultaneidad en el desarrollo de ES directa e indirecta fue causada por la interacción entre los tratamientos de inducción con los medios de expresión $(\mathrm{p}=0)$ (Fig. 5).

Desarrollo de embriones somáticos.- Los embriones cotiledonares aislados de los explantes primarios y transferidos a $\mathrm{MS}+\mathrm{CA}$ se mantuvieron sin cambios aparentes durante 15-20 días y posteriormente murieron, siendo evidente que la presencia de KIN resultó indispensable para el desarrollo de plántulas a partir de ENZ cotiledonares.
El 70\% de las plántulas obtenidas por conversión y desarrollo de ENZ sobrevivieron en condiciones de invernadero (Fig. 1J).

\section{Discusión}

Los resultados obtenidos indicaron que los EZM utilizados como explantes primarios, por estar formados por tejidos muy juveniles, son materiales adecuados para inducir la expresión de capacidades morfogénicas en medio MS suplementado con Vitaminas B5 y con los reguladores de crecimiento ensayados en los diferentes tratamientos. Se sabe que los tejidos de explantes jóvenes responden favorablemente a la acción de los reguladores de crecimiento, poseen un alto grado de actividad meristemática y tienden a mostrar in vitro mayor plasticidad que los tejidos adultos (Ozarowski \& Thiem 2013). Por lo tanto, la alta capacidad morfogénica observada en EZM de P. maliformis, la cual se mantuvo durante un periodo prolongado a través de varios subcultivos, se puede atribuir, en gran parte, al estado juvenil de sus tejidos. Una respuesta semejante se reportó en explantes (EZM, hipocótilos y cotiledones) de Eucalytus globulus Labill. en los que el callo embriogénico obtenido se subcultivó durante 9 meses sin perder su potencial embriogénico (Gómez et al. 2006).

En cuanto al medio de cultivo utilizado, los resultados de este trabajo concuerdan con los de Da-Silva et al. (2009), quienes reportaron embriogénesis no zigótica en cultivos de EZM de $P$. cincinnata utilizando el mismo medio básico. Por otra parte, los requerimientos de temperatura de los cultivos in vitro tienden a estar en el rango de 23 a $27^{\circ} \mathrm{C}$ (El-Esawi 2016); para $P$. malifor- 
mis una temperatura de $24 \pm 2{ }^{\circ} \mathrm{C}$ facilitó la expresión adecuada de respuestas embriogénicas. La incubación de los explantes en oscuridad continua durante la etapa de inducción resultó favorable para los procesos de dediferenciación y rediferenciación celular observados. Según El-Esawi (2016), los tejidos de los explantes cultivados en oscuridad suprimen la diferenciación, por ejemplo, de plastidios en cloroplastos; además, las condiciones de oscuridad pueden inhibir la germinación precoz de embriones jóvenes.

La incubación de los explantes en fotoperiodo de 16 horas durante la fase de expresión, resultó en un gran número de explantes con respuesta embriogénica; al respecto, ChiaveriniPinto et al. (2010), han indicaron que la oscuridad fue crucial para la inducción de yemas adventicias en Passiflora alata Curtis; no obstante, la influencia determinante de la luz sobre la capacidad morfogénica de los explantes también ha sido reportada en cultivos de Passiflora suberosa L. (Boffino-de-Almeida-Monteiro et al. 2000) y de otros grupos de plantas (Pérez-Pérez et al. 2017). En general, las condiciones de iluminación son particularmente importantes y existen evidencias del efecto de la calidad de la luz, sobre la formación y multiplicación de embriones somáticos, lo cual varía según la especie y el estado fisiológico de desarrollo del tejido cultivado (Rodríguez-Sahagu et al. 2011).

El tipo y concentración del agente gelificante utilizado (Phytagel ${ }^{\odot}, 2800 \mathrm{mgL}^{-1}$ ) demostró ser un soporte adecuado para los procesos de inducción en EZM y posterior expresión de respuestas morfogénicas; no obstante, en pasifloras ha sido exitoso el uso tanto de Phytagel como de Agar-Agar (Da-Silva et al. 2009, Ozarowski \& Thiem 2013).

Los EZM utilizados en este trabajo demostraron tener una gran capacidad para producir ENZ en diferentes estados de desarrollo, tanto por vía directa como indirecta (Figura $1 \mathrm{H}$ ) en presencia de RC. Si bien, en los tratamientos control no ocurrió embriogénesis no zigótica, si se observó la germinación de embriones zigóticos; al cabo de 15 días de cultivo, estos embriones desarrollaron plántulas de 6 a $7 \mathrm{~cm}$. La ausencia de ENZ en el tratamiento control se debe, en parte, a que en la mayoría de especies los RC son necesarios para inducir dicho proceso; observándose que las auxinas y citoquininas son factores clave para determinar la respuesta embriogénica, probablemente debido a su participación en la regulación del ciclo celular, división y diferenciación (Gaj 2011, Fehér 2008). En el total de explantes de los tratamientos control se observó que, en el medio de inducción, 99\% de los embriones zigóticos germinaron; además, en la siembra de cerca de 400 embriones zigóticos en medio MS también se cuantificó 98\% de germinación (ensayos preliminares, datos no mostrados).

Durante los últimos años, son pocos los estudios reportados sobre embriogénesis no zigótica en pasifloras (Da-Silva et al. 2009, Pinto et al. 2010, Pinto et al. 2011, Rocha et al. 2012, Rosa \& Dornelas 2012, Ozarowski \& Thiem 2013) y para P. maliformis este es el primero. En $P$. maliformis, la presencia de BA solo o en combinación con 2,4-D fue indispensable para la formación de ES (T10 y T2), lo cual confirma que el BA y el 2,4-D son factores determinantes en la respuesta embriogénica de varias pasifloras (Ozarowski \& Thiem 2013, Da-Silva et al. 2009).

La mayoría de los tratamientos reportados para inducir embriogénesis no zigótica pueden afectar el balance auxinico entre las células del explante cultivado. Explantes con altos niveles de auxinas endógenas pueden presentar mayores respuestas sin requerir auxinas exógenas. En el caso de $P$. maliformis se observó que en aquellos tratamientos en los que se adicionó al medio de inducción solo la auxina, el porcentaje de explantes embriogénicos no fue significativo (Fig. 2). Así como en otros procesos morfogénicos, el desarrollo de embriones no zigóticos puede ocurrir bajo condiciones libres de auxinas, lo cual indica que las células adquieren la capacidad para sintetizarlas; se ha reportado que la síntesis de auxinas y su transporte polar es un paso clave en la formación de meristemos fundamentales para el desarrollo del embrión (Fehér 2008).

Rosa y Dornelas (2012) reportaron que las primeras y mayores respuestas embriogénicas en Passiflora foetida L. se observaron en la inserción de los cotiledones de embriones zigóticos en medios suplementados con auxina y citoquinina; esta formación de ENZ mayoritariamente en los bordes de los cotiledones, las inserciones cotiledonares y en la radícula, también se observó en los explantes de $P$. maliformis cultivados en el presencia de BA+2,4-D (T2), y que posteriormente fueron transferidos a medio con CA (EI) (Fig. 2). Adicionar CA al medio de expresión conlleva una rápida adsorción de reguladores de crecimiento tanto endógenos como exógenos, lo cual puede influir en los sistemas regenerativos de Passiflora (Ozarowski \& Thiem 2013), resultando beneficioso para la iniciación de procesos embriogénicos no zigóticos observados en el $60 \%$ de los explantes cultivados.

La mayoría de modelos embriogénicos inducidos in vitro indican que el 2,4-D es requerido para la iniciación del programa celular vía embriogénesis no zigótica (Guzzo et al. 2004); en $P$. maliformis, en los tratamientos T7 y T8 (Fig. 2), en los que solo se adicionó al medio de inducción 2,4-D (1 y 3 mgL-1, respectivamente), la estimulación de la capacidad embriogénica no superó el 17\% en los medios de expresión EI y EII, mientras que en el tratamiento T9 + EI ( $5 \mathrm{mgL}^{-1}$ 2,4-D) se observó 30\% de explantes embriogénicos. Las auxinas, como el 2,4-D, sirven para inducir la formación de células embriogénicas, posiblemente, por la activación de un gen que inicia la diferenciación; también pueden promover el incremento de poblaciones celulares embriogénicas a través de divisiones celulares repetitivas, mientras simultáneamente se suprime la diferenciación celular y se convierten en embriones (El-Esawi 2016).

En los tratamientos en los que se combinó el 2,4-D, en cualquiera de sus tres concentraciones, con las dos citoquininas, los porcentajes más altos de estimulación de la capacidad embriogénica se obtuvieron cuando los explantes fueron transferidos al medio de expresión con CA (EI), lo cual puede deberse a que los embriones no zigóticos son muy sensibles a sustancias tóxicas y volátiles producidas durante el cultivo in vitro. Por lo tanto, la adición de CA al medio, principalmente durante la fase de diferenciación, es una alternativa de efecto benéfico por su actividad pues además de favorecer los procesos de crecimiento y de potencializar el efecto de los fitorreguladores, el CA adicionado a los medios de cultivo ejerce un control positivo de la oxidación tanto en el medio de cultivo como en el tejido vegetal propiamente dicho, reduciendo considerablemente la pérdida de material vegetal por necrosis causada por la oxidación. De acuerdo con Roca y Mroginski (1993), la oxidación de algunos compuestos químicos como taninos, fenoles y polifenoles es uno de los aspectos de más difícil manejo en cultivos in vitro, y es causal de la inhibición de las actividades enzimáticas relacionas con la síntesis de proteínas, 
y de la respuesta de los tejidos a las diferentes fitohormonas. Por esta razón, la oxidación de los tejidos vegetales cultivados bajo condiciones in vitro termina con la supresión total de toda respuesta de crecimiento y desarrollo del tejido, y una posterior necrosis del mismo (Pedroza-Manrique 2007, Pedroza-Manrique 2009). Por tanto, la presencia del CA es importante para garantizar un buen desarrollo fisiológico de las plántulas y de esta forma contribuir a su viabilidad (Pedroza-Manrique 2009).

Los porcentajes de explantes que presentaron embriogénesis directa tendió a disminuir en los medios suplementados únicamente con KIN o 2,4-D (Fig. 3); no obstante, se observó un incremento en el porcentaje de explantes embriogénicos, al transferir los explantes del medio suplementado con 2,4-D ( $5 \mathrm{mgL}^{-1}$ ) a MS con CA (EI), indicando una alta capacidad de respuesta morfogénica de EZM tal como lo reportaron Da-Silva et al. (2009) para P. cincinnata; esta respuesta se debe, en muchos casos, a la disminución brusca del nivel de 2,4-D que desata el inicio del proceso embriogénico (Fehér 2008).

El desarrollo de embriogénesis indirecta en $P$. maliformis en presencia de la combinación citoquinina-auxina (T2,1 $\mathrm{mgL}^{-1}$ $\mathrm{BA}+3 \mathrm{mgL}^{-1}$ 2,4-D) concuerda con resultados similares para otras pasifloras (Ozarowski \& Thiem 2013). Pinto et al. (2011) observaron formación de callos embriogénicos en embriones zigóticos maduros de P. edulis en medio MS suplementado con 2,4-D (4 - $\left.32 \mathrm{mgL}^{-1}\right)$ solo o combinado con BA ( $\left.1 \mathrm{mgL}^{-1}\right)$. DaSilva et al. (2009) obtuvieron a partir de EZM embriogénesis somática de $P$. cincinnata, pero el mayor número de embriones no zigóticos se indujo en medio con 2,4-D $\left(32 \mathrm{mgL}^{-1}\right)+\mathrm{BA}(1$ $\left.\mathrm{mgL}^{-1}\right)$. Rocha et al. (2012) y Pinto et al. (2010) estudiando la embriogénesis en MS suplementado con 2.4-D $\left(4 \mathrm{mgL}^{-1}\right)+\mathrm{BA}$ $\left(1 \mathrm{mgL}^{-1}\right)$ y, Rosa y Dornelas (2012), también comprobaron que concentraciones de 2,4-D (3 y $4 \mathrm{mgL}^{-1}$ ) combinados con BA $\left(1 \mathrm{mgL}^{-1}\right)$ fueron las más efectivas para la regeneración de plantas a partir de callos de $P$. foetida; así mismo, reportaron la conversión de embriones somáticos bien formados a plantas, alcanzando el $60 \%$ de plantas aclimatizadas en invernadero. No obstante, Tavares et al. (2015) obtuvieron altos porcentajes (90\%) de regenerantes normales a partir de embriones zigóticos inmaduros en medio MS + vitaminas B5 sin 2,4-D, en contraste con los valores de plántulas regeneradas a partir de EZM hasta entonces reportadas por otros autores $(60 \%)$.

Por tanto, se ha comprobado que la respuesta embriogénica somática de Passiflora, ocurre cuando se utiliza como medio básico MS o MS con vitaminas B5, como ocurrió en este estudio para P. maliformis y en Passiflora miniata Vanderpl. y Passiflora speciosa Gardner (Tavares et al. 2015), en presencia o no de BA y 2,4-D, aunque la combinación no siempre fue necesaria.

En cuanto al uso exclusivo de 2,4-D en concentraciones altas (5 $\mathrm{mgL}^{-1}$ ) y su efecto sobre la embriogénesis indirecta, los resultados de este estudio concuerdan con la frecuencia de callo con ENZ obtenida en $P$. cincinnata, cuando aumentó la concentración de 2,4-D (4 mgL $\mathrm{mg}^{-1}$ 2,4-D) (Da-Silva et al. 2009). Los resultados confirman que una mayor concentración de auxinas que de citoquininas en el medio, también indujo embriogénesis no zigótica en Passiflora, lo cual respalda protocolos eficientes en otras especies, en las que la inducción de embriogénesis somática se ha conseguido principalmente con el uso de auxinas y, de ellas, la que se ha utilizado con más frecuencia es el ácido 2,4-diclorofenoxiacético (2,4-D) (Viñas \& Jiménez 2011, Tovar et al. 2016).
En el caso de los explantes en los que se desarrolló simultáneamente embriogénesis no zigótica directa e indirecta (Fig. 5) la acción de las citoquininas (BA y KIN) fue efectiva, aunque el porcentaje de explantes con este tipo de respuesta fue inferior en comparación con aquellos en los que ocurrió un único tipo de embriogénesis (directa o indirecta).

Loyola-Vargas et al. (2008) plantearon que los principales factores involucrados en la estimulación de la embriogénesis y el tipo (directa o indirecta) de morfogénesis depende de la naturaleza, concentración y tiempo de exposición a las fitohormonas empleadas, estado y balance de las fitohormonas endógenas, la fuente y estado fisiológico (la capacidad para responder) del explante, el medio de cultivo y las condiciones de cultivo utilizadas; por tanto, la interacción entre estos factores determina, en gran parte, la inducción y expresión de un modo específico de diferenciación celular y desarrollo (Gaj 2011).

El limitado desarrollo de regenerantes en medio MS+CA pudo deberse a la separación de los embriones del callo o del explante inicial en el momento de ser transferidos, y al efecto (negativo) acumulativo del CA durante la fase de crecimiento y desarrollo, contrario a lo reportado para $P$. miniata y $P$. speciosa (Tavares et al. 2015); en ese estudio para el desarrollo de plántulas, se recuperaron embriones no zigóticos aislados y se transfirieron a medio MS+Vit B5, en ausencia de mioinositol y sustituyendo el Phytagel por Agar.

Los resultados registrados al final de la etapa de expresión (90 días) indicaron que los regenerantes de $P$. maliformis requieren la presencia de KIN para el crecimiento y desarrollo de plántulas. En pasifloras existen pocos datos sobre conversión de embriones somáticos a plántulas; esta conversión difiere entre genotipos, especies y sistemas de cultivo, y es un proceso regulado por acción génica; no obstante, es una regulación independiente del control que realizan los genes sobre la embriogénesis (Fehér 2008). Los problemas que surgen durante el proceso de conversión son atribuidos, en muchos casos, a morfologías atípicas o a la inmadurez de los embriones no zigóticos formados.

En conclusión, debe enfatizarse que este estudio es el primer trabajo en el que se reconoce el potencial embriogénico de EZM de $P$. maliformis y se induce exitosamente una respuesta embriogénica no zigótica a través de rutas directas e indirectas. La mayor cantidad de explantes embriogénicos (70\%) se cuantificó en los tratamientos de inducción suplementados con $1 \mathrm{mgL}^{-1}$ de BA y transferidos a medio de expresión sin reguladores de crecimiento y $1 \mathrm{mgL}^{-1}$ de $\mathrm{BA}+3 \mathrm{mgL}^{-1}$ de 2,4-D transferidos a medio de expresión con CA (60\%). El $70 \%$ de las plantas regeneradas se desarrollaron con éxito en condiciones de invernadero.

El protocolo de embriogénesis no zigótica propuesto para $P$. maliformis constituye un referente para el desarrollo de dicho proceso en otras especies silvestres de Passiflora con fines de aprovechamiento y de mejoramiento para su explotación comercial.

\section{Agradecimientos}

Los autores del trabajo expresan su agradecimiento al Laboratorio de Cultivo de Tejidos Vegetales (Grupo de investigación BIOPLASMA) de la Universidad Pedagógica y Tecnológica de Colombia (UPTC), por la financiación aportada para el desarrollo de la investigación. 


\section{Literatura citada}

Abreu P.P., M.M Souza, E.A. Santos, et al. 2009. Passion flower hybrids and their use in the ornamental plant market:perspectives for sustainable development with emphasis on Brazil. Euphytica 166:307-315. doi http://dx.doi.org/10.1007/ s10681-008-9835-x.

Aguirre-Morales A.C., M.M. Bonilla-Morales \& C.M. Caetano. 2016. Passiflora franciscoi, a new species of Passiflora subgenus Astrophea (Passifloraceae) from Colombia. Phytotaxa 252(1):5662. DOI: http://dx.doi.org/10.11646/phytotaxa.252.1.5

Anthony P., W. Otoni, J. Power, et al. 1999. Protoplasts isolation, culture, and plant regeneration from Passiflora. Method. Molec. Biol. 111:169-181. http://dx.doi.org/10.1385/159259-583-9:169

Boffino-de-Almeida-Monteiro A.C., G. Tokio-Nakazawa, B.M. Januzzi-Mendes, et al. 2000. Regeneraçáo in vitro de Passiflora suberosa a partir de discos foliares. Scientia Agricola 57(3):571-573. http://dx.doi.org/10.1590/S010390162000000300033

Chiaverini-Pinto A.P., A.C. Monteiro-Hara, L. C. Libori-Stipp, et al. 2010. In vitro organogenesis of Passiflora alata. In Vitro Cellular \& Developmental Biology - Plant 46(1):28-33. http://dx.doi.org/10.1007/s11627-009-9251-5

Da-Silva M.L., D.L. Paim-Pinto, M.P Guerra, et al. 2009. A novel regeneration system for a wild passion fruit species (Passiflora cincinnata Mast.) based on somatic embryogenesis from mature zygotic embryos. Plant Cell Tissue and Organ Culture 99:47-54. http://dx.doi.org/10.1007/s11240-009-9574-2

El-Esawi M.A. 2016. Nonzygotic Embryogenesis for Plant Development. En M. Anis \& N. (eds) Ahmad (Eds.), Plant Tissue Culture: Propagation, Conservation and Crop Improvement. (pp. 583-598). Singapore: Springer. http://dx.doi. org/10.1007/978-981-10-1917-3_25

Fehér A. 2008. The initiation phase of somatic embryogenesis: what we know and what we don't. Acta Biologica Szegediensis 52(1): 53-56. Recuperado a partir de http://www.sci.uszeged.hu/ABS

Gaj, M.D. 2011. Somatic embryogenesis and plant regeneration in the culture of Arabidopsis thaliana (L.) Heynh. immature zygotic embryos. En T. Thorpe \& E. (eds) Yeung (Eds.), Plant Embryo Culture. Methods in Molecular Biology (Methods and Protocols) (pp. 257-265). Springer. http:// dx.doi.org/10.1007/978-1-61737-988-8_18

Gamborg O.L., R.A Miller \& K. Ojima. 1968. Nutrient requirements of suspension cultures of soybean root cells. Experimental Cell Research 50:151-158. https://doi.org/10.1016/00144827(68)90403-5

Gómez C., M. Uribe, D. Ríos, et al. 2006. Inducción de callo embriogénico en Eucalyptus globulus Labill. Interciencia 31(10):734738. http://www.redalyc.org/pdf/339/33912106.pdf.

Guzzo F., S. Ceoldo, F. Andreetta, et al. 2004. In vitro culture from mature seeds of Passiflora species. Scientia Agricola 61(1):108113. http://doi.org/10.1590/S0103-90162004000100018

Hansen A., L. Gilbert, B. Simpson, et al. 2006. Phylogenetic relationships and chromosome number evolution in Passiflora. Systematic Botany 31:138-150. http://doi.org/10.1600/ 036364406775971769

Jørgensen P., N. Muchhala \& J.M. MacDougal. 2012. Passiflora unipetala, a new bat-pollinated species of Passiflora supersect (Passifloracea). Tacsonia 22:174-179. doi: http://dx.doi. org/10.3417/2011095

Kanwar J.K. \& S. Kumar. 2008. In vitro propagation of Gerbera- A Review. Horticultural Science (HORTSCI) 35(1):35-44. http://www.agriculturejournals.cz/publicFiles/00765.pdf.

Linnaeu C. 1753. Species Plantarum. Stockholm, Sweden.

Loyola-Vargas V., C. De-la-Peña, R.M. Galaz-Ávalos, et al. 2008. Plant Tissue Culture. En J. Walker \& R. Rapley (Eds.), Molecular Biomethods Handbook (Second, pp. 875-904). Nueva Jersey, USA: Humana Press. http://doi.org/10.1007/978$1-60327-375-6$

Melo-Vieira L., D.I Rocha, M. Futia-Taquetti, et al. 2014. In vitro plant regeneration of Passiflora setacea D. C. (Passifloraceae): the influence of explant type, growth regulators, and incubation conditions. In Vitro Cellular \& Developmental Biology - Plant 50: 738. http://doi.org/10.1007/s1 1627-014-9650-0
Moran-Robles M. J. 1978. In vitro vegetative multiplication of axillary buds of P.edulis var. flavicarpa Degener and P. mollissima Bairley. Fruits 33:701-715.

Murashige T. \& F. Skoog. 1962. A revised medium for rapid growth and bioassays with tobacco tissue cultures. Physiologia Plantarum 15, 473-479. https://doi.org/10.1111/j.1399-3054.1962. tb08052.x

Nakayama, F. 1966. Cultivo in vitro de tejidos de Passiflora caerulea. Revista de la Facultad de Agronomía de la Universidad Nacional de La Plata, 42, 63-74.

Ocampo J. 2013. Diversity and Distribution of Passifloraceae in the Department of Huila in Colombia. Acta Biológica Colombiana 18(3): 511-516. http://www.scielo.org.co/pdf/abc/ v18n3/v18n3a10.pdf

Ocampo J., G. Coppens \& A. Jarvis. 2010. Distribution of the Genus Passiflora L. Diversity in Colombia and Its Potential as an Indicator for Biodiversity Management in the Coffee Growing Zone. Diversity 2: 1158-1180. http://doi. org $/ 10.3390 / \mathrm{d} 2111158$

Ozarowski M. \& B. Thiem. 2013. Progress in micropropagation of Passiflora spp. to produce medicinal plants: A mini-review. Brazilian Journal of Pharmacognosy 23(6):937-947. http:// doi.org/10.1590/S0102-695X2013000600011

Pacheco G., M.J. Simãoa, M.G.Vianna, et al. 2016. In vitro conservation of Passiflora. A review. Scientia Horticulturae 211(November):305-311. http://doi.org/10.1016/j.scienta.2016.09.004

Pedroza-Manrique J. 2009. Efecto del carbón activado , ácido indolacético (AIA) y bencil amino purina (BAP) en el desarrollo de protocormos de Epidendrum elongatum Jacq bajo condiciones in vitro. Revista Colombiana de Biotecnología 211(1):17-32. http://www.scielo.org.co/scielo. php?script $=$ sci_arttext\&pid $=$ S0123-34752009000100003

Pedroza-Manrique J. A. 2007. Efecto del medio básico, carbón activado, ácido giberélico y calidad de luz en la germinación in vitro de Masdevallia auropurpurea Reich. Revista Científica UD (9): 117-141. http://revistas.udistrital.edu.co/ojs/index. $\mathrm{php} / \mathrm{revcie} /$ article/view/354/534

Pérez-Pérez J. L., T. Blanco-Tirado, L. García-Rodríguez, et al. 2017. Influencia del tipo e intensidad de luz en la formación y multiplicación de embriones somáticos de soya. Revista Colombiana de Biotecnología 14(2012):1-9. https://revistas.unal. edu.co/index.php/biotecnologia/article/view/37413/40416.

Pinto D.L, B. Barros, L. Viccini. 2010. Ploidy stability of somatic embryogenesis-derived Passiflora cincinnata Mast. plants as assessed by flow cytometry. Plant Cell, Tissue and Organ Culture 103(1):1-79. http://doi.org/10.1007/s11240-010-9756-y

Pinto P., A.M. De Almeida, M.M. Rego, et al. 2011. Somatic embryogenesis from mature zygotic embryos of commercial passionfruit (Passiflora edulis Sims) genotypes. Plant Cell, Tissue and Organ Culture (PCTOC) 107:521-530. https:// doi.org/10.1007/s11240-011-0003-y

Reis L.B., M.L. Silva, A.B Lima, et al. 2007. Agrobacterium rhizogenes-mediated transformation of passionfruit species: Passiflora cincinnata and P. edulis f. flavicarpa. ISHS Acta Horticulturae 738:425-431. http://doi.org/10.17660/ ActaHortic.2007.738.51

Roca, W. M. \& L. A Mroginski. 1993. Cultivo de tejidos en la agricultura: fundamentos y aplicaciones. (W.M. Roca \& L.A. Mroginski, Eds.). Cali, Colombia.: CIAT-Centro Internacional de Agricultura Tropical.

Rocha D.I., L.M. Vieira, F.A.O. Tanaka, et al. 2012. Somatic embryogenesis of a wild passion fruit species Passiflora cincinnata Masters: histocytological and histochemical evidences. Protoplasma 249(3):747-758. http://doi.org/10.1007/ s00709-011-0318-x

Rodríguez-Sahagu A., G. Acevedo-Hernández, B. Rodríguez-Domínguez, et al. 2011. Effect of light quality and culture medium on somatic embryogenesis of Agave tequilana. Plant Cell, Tissue and Organ Culture (PCTOC), 104:271-275. http:// doi.org/10.1007/s11240-010-9815-4

Rosa Y.B. \& M.C. Dornelas. 2012. In vitro plant regeneration and de novo differentiation of secretory trichomes in Passiflora foetida L. (Passifloraceae). Plant Cell, Tissue and Organ Culture (PCTOC) 108(1):91-99. http://dx.doi.org/10.1007/ s11240-011-0016-6 
Tavares D., M. Cansian, C. Carvalho, et al. 2015. Embryogenic potential of immature zygotic embryos of Passiflora : a new advance for in vitro propagation without plant growth. Plant Cell, Tissue and Organ Culture (PCTOC) 122(3):629-638. http://doi.org/10.1007/s11240-015-0796-1

Tovar V., P. Delgado, A. Martínez, et al. 2016. Embriogénesis somática en madroño (Arbutus xalapensis). BOSQUE 37(3):519-525. http://doi.org/10.4067/S0717-92002016000300009

Veiga-Barbosa L., S. Mira, M.E. González-Benito, et al. 2013. Seed germination, desiccation tolerance and cryopreservation of Passiflora species. Seed Science and Technology 41(1):8997. http://dx.doi.org/10.15258/sst.2013.41.1.08
Viñas M., \& V. Jiménez. 2011. Factores que influyen en la embriogénesis somática in vitro de palmas (Arecaceae). Revista Colombiana de Biotecnología 13(2011): 1-15. http://doi. org/10.15446/rev.colomb.biote

Zerbini, F.M., W.C. Otoni. \& M.L. Vieira, C. 2008. Passionfruit. En Kole C. \& Hall T.C. (Eds.). A Compendium of transgenic crop plants. Compendium of transgenic crop plants. v.5, Tropical and Subtropical Fruit and Nuts. ${ }^{\text {st }}$ ed. John Wiley \& Sons, New York. pp. 213-234. 